\title{
Clinical usefulness of the S-O clip during colorectal endoscopic submucosal dissection in difficult-to-access submucosal layer
}

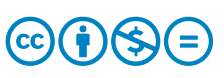

\author{
Authors \\ Institutions \\ 1 Department of Gastroenterology and Metabolism, \\ Hiroshima University Hospital, Hiroshima, Japan \\ 2 Department of Endoscopy, Hiroshima University \\ Hospital, Hiroshima, Japan.
}

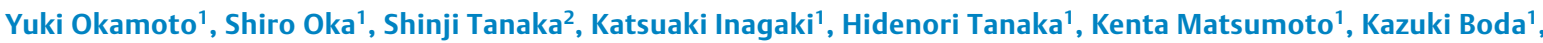
Ken Yamashita', Kyoku Sumimoto², Yuki Ninomiya², Kazuaki Chayama'

submitted 4.6 .2019

accepted after revision 11.9 .2018

\author{
Bibliography \\ DOI https://doi.org/10.1055/a-1093-0681 | \\ Endoscopy International Open 2020; 08: E437-E444 \\ (c) Georg Thieme Verlag KG Stuttgart · New York \\ elSSN 2196-9736
}

\section{Corresponding author}

Shiro Oka, PhD, Department of Gastroenterology and Metabolism, Hiroshima University Hospital, 1-2-3, Kasumi, Minami-ku, Hiroshima 734-8551, Japan

Fax: +81-82-257-5939

oka4683@hiroshima-u.ac.jp

\section{ABSTRACT}

Background and study aims In colorectal endoscopic submucosal dissection (ESD), the S-O clip improves the accessibility to the submucosal layer of the colon. However, its safety and usefulness in difficult colorectal ESDs are unclear. Thus, in this study, we aimed to assess the effectiveness of the S-O clip in colorectal ESD in the difficult-to-access submucosal layer.

Patients and methods From January 2016 to December 2016, 189 consecutive cases of colorectal ESD were performed at Hiroshima University Hospital before the S-O clip was introduced. Between January 2017 and June 2018, among 271 consecutive colorectal ESD cases, 41 cases were performed colorectal ESD using the S-O clip. We compared outcomes between the two groups (41 cases with S-O clip [use group] and 189 cases without S-O clip [non-use group]) using propensity score matching.

Results Prior to propensity score matching, 41 cases with the S-O clip (use group) and 189 cases without the S-O clip (non-use group) were extracted. The degree of submucosal fibrosis was more severe and the procedure time was longer in the use group than in the non-use group. In the use and non-use groups, en bloc resection (100\% vs. $94.7 \%$ ) and complete en bloc resection ( $100 \%$ vs. $92.6 \%$ ) rates were satisfactory. After propensity score matching, 33 cases in each group were extracted. As a result, complete en bloc resection rate was significantly higher in the use group than in the non-use group ( $100 \%$ vs. $84.9 \%$ ).

Conclusion The S-O clip is effective and can be used safely in colorectal ESD in the difficult-to-access submucosal layer.

traction or a combination of special equipment may be required. It is particularly difficult to use such methods in the proximal colon. In 2016, a new traction device, the "S-O clip (Zeon Medical)," was developed for maintaining good operability during submucosal dissection by clipping at a desired position [23, 24]. Because of its usefulness, the $\mathrm{S}-\mathrm{O}$ clip has also been applied not only in colorectal ESD but also in gastric or duodenal ESD [25-27]. There are a few reports on the safety and usefulness of the S-O clip in colorectal ESD [28]. However, there have been no reports on difficult colorectal ESD cases. Thus, in this study, we assessed the effectiveness and safety of the S-O clip 
based on outcomes of colorectal ESD in the difficult-to-access submucosal layer performed using the S-O clip.

\section{Patients and Methods}

\section{Patients}

In this retrospective single-center study, we analyzed outcomes of colorectal ESD performed at Hiroshima University Hospital between January 2016 and June 2018. During this period, we performed colorectal ESD in 451 consecutive patients with 460 cases. From January 2016 to December 2016, 182 patients with 189 cases underwent colorectal ESD without S-O clip (before group; 2 patients with 2 cases that underwent rectal ESD performed using the clip-with-line method were excluded) prior to the introduction of THE S-O clip. Between January 2017 and June 2018, 269 patients with 271 cases underwent colorectal ESD (after group; 6 patients with 6 cases that underwent rectal ESD performed using the clip-with-line method were excluded). Moreover, 41 patients with 41 cases underwent colorectal ESD with the S-O clip. The S-O clip was correctly applied in all patients and did not drop out in any case. Here, we defined 189 cases in the before group as the non-use group and 41 cases with the $\mathrm{S}-\mathrm{O}$ clip in the after group as the use group, and performed propensity score matching (adjusted for sex, age, tumor localization, tumor size, growth type of tumor, degree of submucosal fibrosis, device type, rate of retrograde approach, scope operability, and operator experience value). As a result, 33 cases were extracted from each group, and the clinicopathological findings and outcomes were compared (> Fig. 1).

The study was performed in accordance with the Declaration of Helsinki. All patients were informed of the risks and benefits of ESD, and each patient provided written informed consent for use of patient data. This study was approved by the Institutional Review Board of Hiroshima University Hospital (UMIN000016197, registration date: January 14, 2015).

\section{Indications for colorectal ESD}

Indications for colorectal ESD were defined using criteria proposed by the Japan Gastroenterological Endoscopy Society [29] and the Japanese Society of Gastroenterology [30]. ESD was indicated for tumors that required en bloc resection and in which en bloc resection using snare endoscopic mucosal resection would be difficult [31]. This included laterally spreading tumors of the nongranular type (particularly the pseudo depressed type), tumors with a type $V_{1}$ pit pattern, carcinomas with submucosal shallow invasions of less than $1000 \mu \mathrm{m}$, large depressed tumors, and large elevated tumors that were probably malignant, including large nodular lesions such as laterally spreading tumors of the granular type. In addition, ESD was indicated for intramucosal tumors with fibrosis caused by biopsies or peristalsis, local residual early-stage carcinomas that developed after endoscopic resection, and sporadic localized tumors associated with chronic intestinal inflammation conditions, including ulcerative colitis.

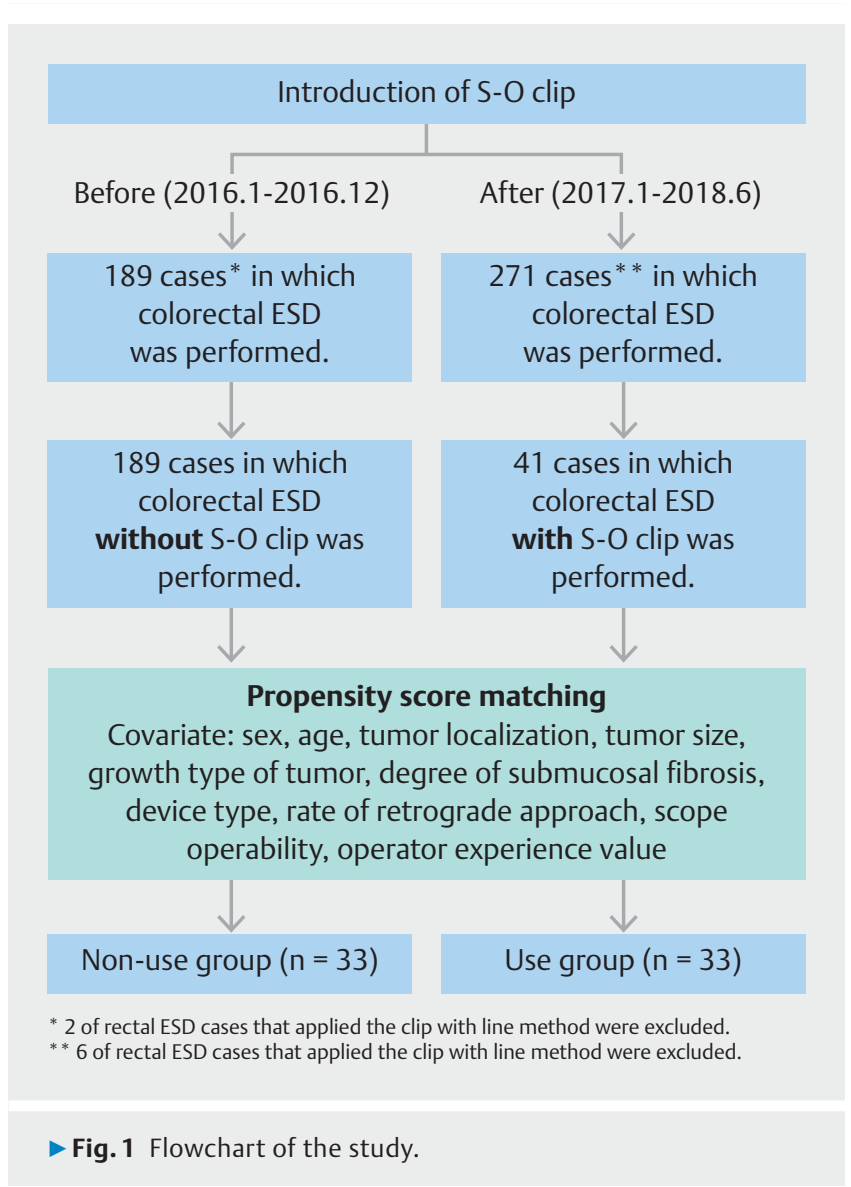

\section{Colorectal ESD procedure}

We performed ESD using a high-resolution video endoscope (CF-H260AZI, PCF-Q260AZI, CF-Q260JI, PCF-H290TI, Olympus, Tokyo, Japan) equipped with a transparent tip hood (ST Hood short type, Fujifilm, Tokyo, Japan), which allowed good visualization and stable dissection. DualKife J (Olympus) was mainly used for incision and submucosal dissection, with an electrosurgical generator (ESG-100, Olympus). When respiratory fluctuation was strong or scope operability was poor, we used ITknife nano (Olympus), whose tip insulator reduced risk of perforation, or SB knife Jr (Sumitomo Bakelite, Tokyo, Japan), which allows safe dissection simply by opening and closing the scissors without moving the knife itself. The pulse-cut slowmode setting $(25 \mathrm{~W})$ was used for mucosal incisions, and the forced coagulation mode $(25 \mathrm{~W})$ was used for submucosal dissection with DualKnife J and ITknife nano. We used the pulsecut fast-mode setting $(30 \mathrm{~W})$ and soft coagulation $(40 \mathrm{~W})$ mode with the SB knife Jr. We mixed equal volumes of $0.4 \%$ sodium hyaluronate (Muco Up, Johnson \& Johnson, New Brunswick, NJ, USA) and $10 \%$ glycerin solution, and added a small amount of indigo carmine $(0.2 \mathrm{~mL}$ per $20 \mathrm{~mL}$ sodium hyaluronate + glycerin). For endoscopic hemostasis, we used hemostatic forceps (Coagrasper, Olympus). The ESD procedure was performed by seven endoscopists with various skill levels. 

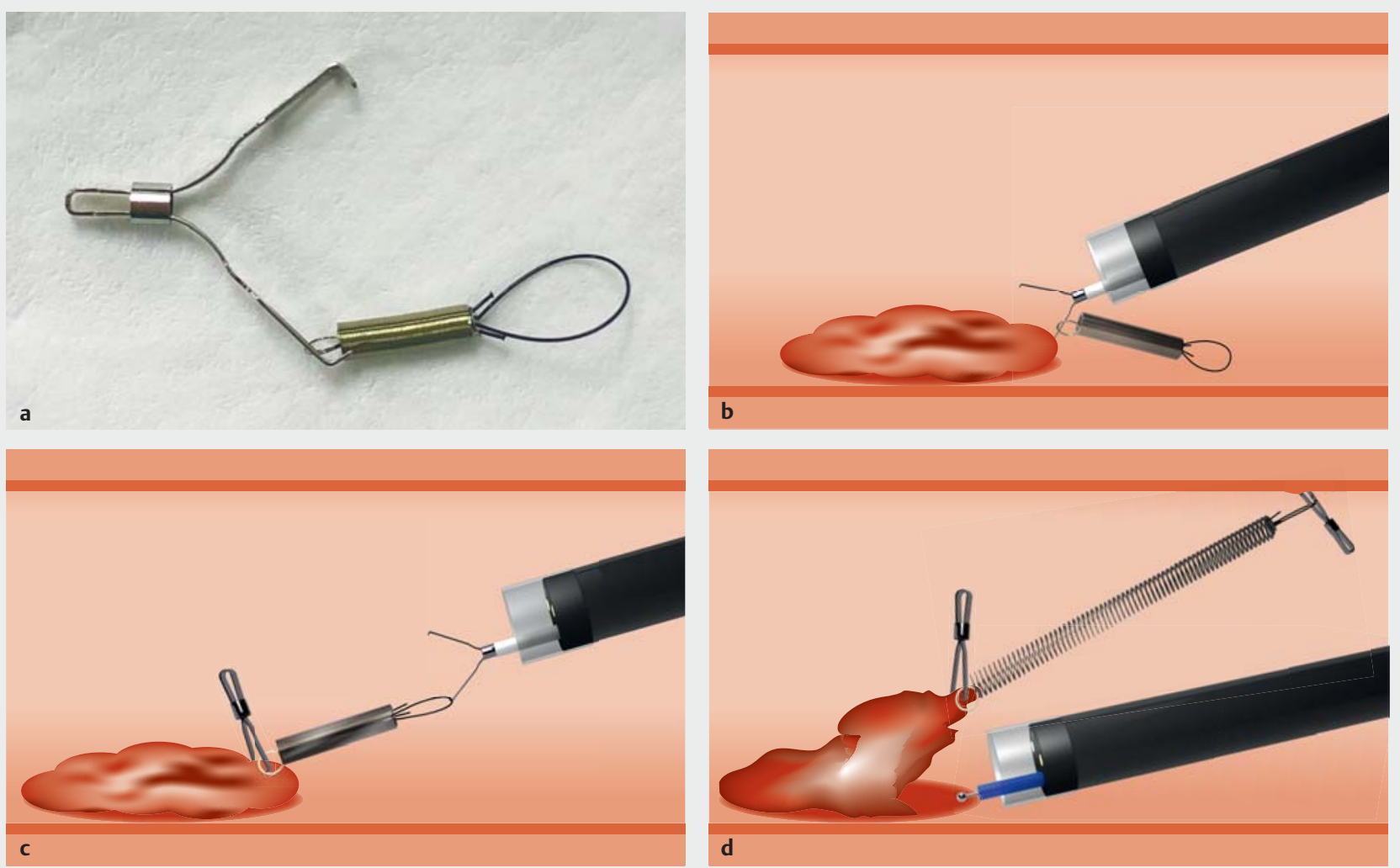

- Fig. 2 a Photo of S-O clip. b S-O clip was placed on the edge of the exfoliated mucosa. c A nylon loop attached to S-O clip was hooked to a normal or long clip. $\mathbf{d}$ The spring tip was fixed at the opposite side of the lesion, at a distance of two folds behind the scope tip.

\section{S-O clip indication and procedure}

We use the S-O clip as needed, particularly when the submucosal layer is difficult to access during submucosal dissection. Indications for use of the $\mathrm{S}-\mathrm{O}$ clip in our hospital are as follows: (1) existence of severe submucosal fibrosis, (2) tumor progression into the diverticula and the appendix, and (3) difficult accessibility of the submucosal layer for the scope. All seven operators equally applied the S-O clip.

After partial submucosal dissection of the tumor, the S-O clip was placed on the edge of the exfoliated mucosa. A nylon loop attached to the S-O clip was hooked to a normal or long clip (HX-610-135 or HX-610-090 L, Olympus). The spring tip (opposite side of the clip) was fixed at the opposite side of the lesion, at a distance of two folds behind the scope tip ( $\triangleright$ Fig. 2). Thereafter, visibility of the submucosal layer was increased, facilitating dissection. After ESD, the nylon loop was cut by the DualKnife J or ITknife nano, and the segment attached to the $\mathrm{S}-\mathrm{O}$ clip was removed from the colon using a collection net (Olympus).

\section{Examination items}

We evaluated clinicopathological characteristics (sex, age, localization, tumor size, growth type of tumor, degree of submucosal fibrosis, pathological findings, type of device, rate of retrograde approach, operability of the endoscope, and operator experience value) and the outcomes (procedure time, en bloc resection rate, complete en bloc resection rate, post hemorrhage rate, and perforation rate). Degree of submucosal fibrosis was classified as no/mild fibrosis or severe fibrosis [32]. Postoperative hemorrhage was defined as a decrease in hemoglobin levels by $2 \mathrm{~g} / \mathrm{dL}$ or more compared with the last recorded preoperative level or any apparent bleeding or massive melena [33]. Complete en bloc resection was confirmed when a segment with negative tumor margins was established histopathologically. Scope operability was classified as good, normal, or poor and was determined depending on whether a sufficient field of view could be maintained with the scope and whether the scope could be moved to the intended site without resistance, as previously reported [11]. 
- Table 1 Comparison of clinicopathological findings between cases before and after introduction of S-O clip.

\begin{tabular}{|c|c|c|c|}
\hline \multirow[t]{2}{*}{ Variables } & \multicolumn{2}{|c|}{ Introduction of S-O clip } & \multirow[t]{2}{*}{$P$ value } \\
\hline & $\begin{array}{l}\text { Before (2016.1- } \\
2016.12) n=189\end{array}$ & $\begin{array}{l}\text { After }(2017.1- \\
2018.6) n=271\end{array}$ & \\
\hline \multicolumn{4}{|l|}{ Sex } \\
\hline - Male & $111(58.7)$ & $170(62.7)$ & \multirow[t]{2}{*}{0.386} \\
\hline - Female & $78(41.3)$ & $101(37.2)$ & \\
\hline Age (years) & $66.9 \pm 10.8$ & $65.5 \pm 10.5$ & 0.234 \\
\hline \multicolumn{4}{|c|}{ Tumor localization } \\
\hline - Right colon & $110(58.2)$ & $144(53.1)$ & \multirow[t]{3}{*}{0.363} \\
\hline - Left colon & $32(16.9)$ & $60(22.1)$ & \\
\hline - Rectum & $47(24.9)$ & $67(24.7)$ & \\
\hline $\begin{array}{l}\text { - Tumor size } \\
(\mathrm{mm})\end{array}$ & $31.5 \pm 17.2$ & $35 \pm 5$ & 0.459 \\
\hline \multicolumn{4}{|l|}{ Growth type } \\
\hline - Polypoid & $26(13.8)$ & $124(45.7)$ & \multirow[t]{2}{*}{$<0.0001$} \\
\hline - Superficial & $163(86.2)$ & $147(54.2)$ & \\
\hline \multicolumn{4}{|c|}{ - Submucosal fibrosis } \\
\hline $\begin{array}{l}\text { - None or } \\
\text { mild }\end{array}$ & $156(82.5)$ & $201(74.2)$ & \multirow[t]{2}{*}{0.0341} \\
\hline - Severe & $33(17.5)$ & $70(25.8)$ & \\
\hline \multicolumn{4}{|l|}{ Histology } \\
\hline - Adenoma & $114(60.3)$ & $140(51.7)$ & \multirow[t]{4}{*}{0.0083} \\
\hline $\begin{array}{l}\text { - Tis carci- } \\
\text { noma }\end{array}$ & $50(26.5)$ & $94(34.7)$ & \\
\hline $\begin{array}{l}\text { - T1a carci- } \\
\text { noma }(< \\
1000 \mu \mathrm{m})\end{array}$ & $3(1.6)$ & $17(6.3)$ & \\
\hline $\begin{array}{l}\text { - T1b carci- } \\
\text { noma }(\geq \\
1000 \mu \mathrm{m})\end{array}$ & $22(11.6)$ & $20(7.4)$ & \\
\hline $\begin{array}{l}\text { - Use of only } \\
\text { Dualknife J }\end{array}$ & $82(43.4)$ & $120(44.3)$ & 0.850 \\
\hline $\begin{array}{l}\text { Retrograde } \\
\text { approach }\end{array}$ & $97(51.3)$ & $133(49.1)$ & 0.636 \\
\hline \multicolumn{4}{|c|}{ Scope operability } \\
\hline $\begin{array}{l}\text { - Good/ } \\
\text { normal }\end{array}$ & $113(59.8)$ & $167(61.6)$ & \multirow[t]{2}{*}{0.692} \\
\hline - Poor & $76(40.2)$ & $104(38.4)$ & \\
\hline $\begin{array}{l}\text { - Use of S-O } \\
\text { clip }\end{array}$ & $0(0)$ & $41(15.1)$ & $<0.0001$ \\
\hline \multicolumn{4}{|l|}{ Operator } \\
\hline - Expert & $183(96.8)$ & $238(87.8)$ & \multirow[t]{2}{*}{0.0006} \\
\hline - Non-expert & $6(3.2)$ & $33(12.2)$ & \\
\hline
\end{tabular}

\section{Statistical analysis}

We attenuated selection bias with respect to S-O clip due to sex, age, tumor localization, tumor size, growth type of tumor, degree of submucosal fibrosis, device type, rate of retrograde approach, scope operability, and operator experience value by using propensity score matching. Propensity scores were calculated using a logistic regression method. After propensity scores were estimated, one-to-one nearest neighbor matching was performed using a caliper set at 0.05 . Student's $t$-test and the Wilcoxon rank-sum test were used to compare the distribution of continuous variables, and the Pearson chi-squared test or Fisher's exact test was used to examine the association between categorical variables and outcomes. $P<0.05$ was considered to be statistically significant. All statistical analyses were performed using JMP version 14 (SAS Institute Inc., Cary, North Carolina, United States).

\section{Results}

Clinicopathological finding of the before group was as follows: $66.9 \pm 10.8$ years old, with a $111 / 78$ male to female ratio. That of the after group was as follows: $65.5 \pm 10.5$ years old, with a $170 / 101$ male to female ratio. The rate of superficial tumors (86.2\% [163/189] vs. $54.2 \%[147 / 271], P<0.0001)$ and the rate of expert operators $(96.8 \%$ [183/189] vs. $87.8 \%$ [238/ $271], P=0.0006)$ were higher in the before group than in the after group. Conversely, the rate of cases with severe submucosal fibrosis ( $25.8 \%$ [70/271] vs. $17.5 \%$ [33/189], $P=0.0341)$ was higher in the after group than in the before group ( $>$ Table 1 ). In addition, rates of en bloc resection (98.5\% [267/271] vs. $94.7 \%$ [179/189], $P=0.0191)$ and complete en bloc resection $(97.8 \%$ [265/271] vs. $92.6 \%$ [175/189], $P=0.0072)$ were higher in the after group than in the before group ( $\downarrow$ Table 2 ). Furthermore, there were four recurrence cases in the before group and 14 cases in the after group, and there was no case of ulcerative colitis. Prior to propensity score matching, in the use group, the clinicopathological finding was as follows: $67.5 \pm 11.2$ years old, with a 29/12 male to female ratio. In addition, 22 cases had severe submucosal fibrosis, and there was difficulty in accessing the submucosal layer in 19 cases. Submucosal fibrosis altitude in the use group was significantly higher than that in the non-use group (53.7\% [22/41] vs. $17.5 \%$ [33/189], $P<$ $0.0001)$. In addition, the proportion of the retrograde approach was significantly lower in the use group than in the non-use group $(31.7 \%$ [13/41] vs. $51.3 \%$ [97/189], $P=0.0227$, [ $>$ Table $3]$ ). With regard to treatment, the treatment time in the use group was significantly longer than that in the non-use group $(120.6 \pm 90.6 \mathrm{~min}$ vs. $78.9 \pm 66.8 \mathrm{~min}, P=0.0001)$. There was no significant difference in en bloc resection rate, which was $100 \%$ $(41 / 41)$ in the use group and $94.7 \%(179 / 189)$ in the non-use group. The complete en bloc resection rate was also comparable at $100 \%(41 / 41)$ in the use group and $92.6 \%(175 / 189)$ in the non-use group. In addition, the rate of intraoperative perforation in the use group was significantly higher than that in the non-use group ( $7.3 \%$ [3/41] vs. $0.5 \%$ [1/189], $P=0.0026)$. Perforation occurred in three cases in the use group due to se- 
- Table 2 Comparison of treatment results between cases before and after introduction of S-O clip.

\begin{tabular}{|c|c|c|c|}
\hline \multirow[t]{2}{*}{ Variables } & \multicolumn{2}{|c|}{ Introduction of S-O clip } & \multirow[t]{2}{*}{$P$ value } \\
\hline & $\begin{array}{l}\text { Before } \\
(2016.1- \\
2016.12) \\
n=189\end{array}$ & $\begin{array}{l}\text { After } \\
(2017.1- \\
2018.6) \\
n=271\end{array}$ & \\
\hline Procedure time (min) & $78.9 \pm 66.8$ & $115 \pm 35$ & 0.442 \\
\hline En bloc resection & $179(94.7)$ & 267 (98.5) & 0.0191 \\
\hline $\begin{array}{l}\text { Complete en bloc } \\
\text { resection }\end{array}$ & $175(92.6)$ & $265(97.8)$ & 0.0072 \\
\hline \multicolumn{4}{|l|}{ Adverse events } \\
\hline - Delayed bleeding & $4(2.1)$ & $7(1.52)$ & 0.747 \\
\hline - Perforation & $1(0.5)$ & $7(2.6)$ & 0.097 \\
\hline \multicolumn{4}{|c|}{ Data are presented as mean \pm SD or number (\%) } \\
\hline
\end{tabular}

vere submucosal fibrosis or poor scope operability before the SO clip was attached. All perforations were successfully closed, and all three cases improved with conservative treatment $(\triangleright$ Table 4).

After propensity score matching, we selected 33 cases in each group (use group: $69.5 \pm 6.5$ years old, $24 / 9$ male to female ratio, non-use group: $58.5 \pm 2.5$ years old, $23 / 10$ male to female ratio; [ Table 5]). In both cases, significant differences in clinical findings were resolved. Complete en bloc resection rate in the use group was significantly higher than that in the non-use group (100\% [33/33] vs. $84.9 \%$ [28/33], $P=0.02$, [ Table 6]).

\section{Discussion}

It is important to ensure a good field of view and effective traction of the lesion is necessary to perform safer and more reliable dissection in colorectal ESD. Ritsuno et al. [28] reported, in a randomized controlled trial of 50 cases, that treatment time is shorter when ESD is performed using the S-O clip for large superficial colorectal tumors. As the $\mathrm{S}-\mathrm{O}$ clip has only recently been introduced, there are limited reports of its use in colorectal ESD cases. Moreover, the literature is insufficient regarding the safety and usefulness of the $\mathrm{S}-\mathrm{O}$ clip especially in cases where it is difficult to approach the submucosal layer. Thus, using propensity score matching, we evaluated the safety and effectiveness of the $\mathrm{S}-\mathrm{O}$ clip in consecutive patients by comparing cases that satisfied the $\mathrm{S}-\mathrm{O}$ clip usage indication with cases where the S-O clip was not used; significant differences in submucosal fibrosis altitude and the rates of retrograde approach were resolved. There was no significant difference in treatment time between both groups, possibly because there were some cases where the submucosal dissection was continued for a relatively long time before using the $\mathrm{S}$ - $\mathrm{O}$ clip although it is supposed to be used as soon as possible when its use is deemed necessary. Complete en bloc resection rate in the use
- Table 3 Comparison of clinicopathological findings between S-O clip use group and non-use group before propensity score matching.

\begin{tabular}{|l|l|l|l|}
\hline Variables & S-O clip & P value \\
\hline Non-use & Use \\
& $\mathbf{n}=\mathbf{1 8 9}$ & $\mathrm{n}=\mathbf{4 1}$ \\
\end{tabular}

\begin{tabular}{|c|c|c|c|}
\hline \multicolumn{4}{|l|}{ Sex } \\
\hline - Male & $111(58.7)$ & $29(70.7)$ & \multirow[t]{2}{*}{0.154} \\
\hline - Female & $78(41.3)$ & $12(29.3)$ & \\
\hline Age (years) & $66.9 \pm 10.8$ & $67.5 \pm 11.2$ & 0.751 \\
\hline \multicolumn{4}{|l|}{ Tumor localization } \\
\hline - Right colon & $110(58.2)$ & $28(68.3)$ & \multirow[t]{3}{*}{0.213} \\
\hline - Left colon & $32(16.9)$ & $8(19.5)$ & \\
\hline - Rectum & $47(24.9)$ & $5(12.2)$ & \\
\hline - Tumor size (mm) & $31.5 \pm 17.2$ & $34.5 \pm 18.1$ & 0.0763 \\
\hline
\end{tabular}

\begin{tabular}{|c|c|c|c|}
\hline \multicolumn{4}{|l|}{ Growth type } \\
\hline - Polypoid & $26(13.8)$ & $8(19.5)$ & \multirow[t]{2}{*}{0.347} \\
\hline - Superficial & $163(86.2)$ & $33(80.5)$ & \\
\hline \multicolumn{4}{|c|}{ Submucosal fibrosis } \\
\hline - None or mild & $156(82.5)$ & $19(46.3)$ & \multirow[t]{2}{*}{$<0.0001$} \\
\hline - Severe & $33(17.5)$ & $22(53.7)$ & \\
\hline
\end{tabular}

\begin{tabular}{|c|c|c|c|}
\hline - Adenoma & $114(60.3)$ & $16(39.0)$ & 0.0051 \\
\hline - Tis carcinoma & $50(26.5)$ & $17(41.4)$ & \\
\hline $\begin{array}{l}\text { - T1 a carcinoma } \\
(<1000 \mu \mathrm{m})\end{array}$ & $3(1.6)$ & $4(9.8)$ & \\
\hline $\begin{array}{l}\text { - T1b carcinoma } \\
(\geq 1000 \mu \mathrm{m})\end{array}$ & $22(11.6)$ & $4(9.8)$ & \\
\hline $\begin{array}{l}\text { - Use of only } \\
\text { Dualknife J }\end{array}$ & $82(43.4)$ & $16(39.0)$ & 0.609 \\
\hline $\begin{array}{l}\text { - Retrograde } \\
\text { approach }\end{array}$ & $97(51.3)$ & $13(31.7)$ & 0.0227 \\
\hline
\end{tabular}

\begin{tabular}{|c|c|c|c|}
\hline \multicolumn{4}{|l|}{ Scope operability } \\
\hline - Good/normal & $113(59.8)$ & $22(53.7)$ & \multirow[t]{2}{*}{0.47} \\
\hline - Poor & $76(40.2)$ & $19(46.3)$ & \\
\hline \multicolumn{4}{|l|}{ Operator } \\
\hline - Expert & $183(96.8)$ & $37(90.2)$ & \multirow[t]{2}{*}{0.061} \\
\hline - Non-expert & $6(3.2)$ & $4(9.8)$ & \\
\hline
\end{tabular}


- Table 4 Comparison of treatment results between S-O clip use group and non-use group before propensity score matching.

\begin{tabular}{|l|l|l|l|}
\hline \multirow{2}{*}{ Variables } & \multicolumn{2}{|c|}{ S-O clip } & P value \\
\cline { 1 - 3 } & $\begin{array}{l}\text { Non-use } \\
\mathbf{n = 1 8 9}\end{array}$ & $\begin{array}{l}\text { Use } \\
\mathbf{n = 4 1}\end{array}$ & \\
\hline Procedure time (min) & $78.9 \pm 66.8$ & $120.6 \pm 90.6$ & 0.0001 \\
\hline En bloc resection & $179(94.7)$ & $41(100.0)$ & 0.132 \\
\hline $\begin{array}{l}\text { Complete en bloc } \\
\text { resection }\end{array}$ & $175(92.6)$ & $41(100.0)$ & 0.0721 \\
\hline Adverse events & & & \\
\hline - Delayed bleeding & $4(2.1)$ & $2(4.9)$ & 0.315 \\
\hline - Perforation & $1(0.5)$ & $3(7.3)$ & 0.0026 \\
\hline Data are presented as mean \pm SD or number (\%) & \\
\hline
\end{tabular}

group was significantly higher than that in the non-use group; this result is considered to be due to improvement of the resection condition with use of the S-O clip. Taken together, we consider that the S-O clip can result in optimal en bloc resection even in cases where the submucosal layer is difficult to access. In addition, the rate of adverse events in the use and non-use groups was low; therefore, we consider that the S-O clip can be used safely.

Obtaining traction to secure the visual field involves application of gravity or a sinker $[12,13]$. However, this method is often ineffective because of inadequate traction. As previously reported, the clip flap method helps increase the accessibility of the submucosal layer for the scope [14]. However, the traction effect is often inadequate and the clip interferes with dissection in some cases. The external forceps method involves use of grasping forceps, which is inserted from the forceps port of the scope, thereby allowing the tumor to be pulled. However, this method is only applicable to rectal lesions [15]. Thin endoscope-assisted ESD requires a second endoscopist to operate the thin endoscope for traction; in addition, insertion of the thin endoscope into the proximal colon is difficult [16, 17]. Although the clip-with-line method is effective for rectal or sigmoid lesions that can be pulled by a thread from outside the anus, its efficacy in the proximal colon is limited $[18,19]$. The clip-and-snare method with a pre-looping technique involves fixing the snare around the transparent hood of the endoscope in advance and pulling a clip using the snare after the clip has been placed. However, this method requires reinsertion of the endoscope $[20,21]$. The magnetic anchor method is advantageous in that it allows for the direction of traction to be changed from outside the body using magnetic force [22]. However, it is expensive and the number of times this device can be used is limited.
- Table 5 Comparison of clinicopathological findings between S-O clip use group and non-use group after propensity score matching.

\begin{tabular}{|l|l|l|l|}
\hline Variables & S-O clip & P value \\
\hline Non-use & Use \\
$n=33$ & $n=33$ \\
\end{tabular}

\begin{tabular}{|c|c|c|c|}
\hline \multicolumn{4}{|l|}{ Sex } \\
\hline - Male & $23(69.7)$ & $24(72.7)$ & \multirow[t]{2}{*}{0.786} \\
\hline - Female & $10(30.3)$ & $9(27.3)$ & \\
\hline Age (years) & $58.5 \pm 2.5$ & $69.5 \pm 6.5$ & 0.281 \\
\hline \multicolumn{4}{|l|}{ Tumor localization } \\
\hline - Right colon & $20(60.6)$ & $23(69.7)$ & \multirow[t]{3}{*}{0.71} \\
\hline - Left colon & $7(21.2)$ & $6(18.2)$ & \\
\hline - Rectum & $6(18.2)$ & $4(12.1)$ & \\
\hline - Tumor size (mm) & $37.5 \pm 12.5$ & $30 \pm 10$ & 0.618 \\
\hline
\end{tabular}

\begin{tabular}{|c|c|c|c|}
\hline \multicolumn{4}{|l|}{ Growth type } \\
\hline - Polypoid & $5(15.1)$ & $6(18.2)$ & \multirow[t]{2}{*}{0.741} \\
\hline - Superficial & $28(84.9)$ & $27(81.8)$ & \\
\hline \multicolumn{4}{|c|}{ Submucosal fibrosis } \\
\hline - None or mild & $17(51.5)$ & $19(57.6)$ & \multirow[t]{2}{*}{0.621} \\
\hline - Severe & $16(48.5)$ & $14(42.4)$ & \\
\hline
\end{tabular}

\begin{tabular}{|c|c|c|c|}
\hline \multicolumn{4}{|l|}{ Histology } \\
\hline - Adenoma & $21(63.6)$ & $14(42.4)$ & \multirow[t]{4}{*}{0.0653} \\
\hline - Tis carcinoma & $7(21.2)$ & $12(36.4)$ & \\
\hline $\begin{array}{l}\text { - T1a carcinoma } \\
(<1000 \mu \mathrm{m})\end{array}$ & $0(0)$ & $4(12.1)$ & \\
\hline $\begin{array}{l}\text { - T1b carcinoma } \\
(\geq 1000 \mu \mathrm{m})\end{array}$ & $5(15.2)$ & $3(9.1)$ & \\
\hline $\begin{array}{l}\text { - Use of only } \\
\text { Dualknife J }\end{array}$ & $11(33.3)$ & $13(39.4)$ & 0.609 \\
\hline $\begin{array}{l}\text { - Retrograde } \\
\text { approach }\end{array}$ & $15(45.5)$ & $13(39.4)$ & 0.618 \\
\hline
\end{tabular}

\begin{tabular}{|l|l|l|l|}
\hline \multicolumn{2}{|l|}{ Scope operability } & \multicolumn{1}{|l}{1} \\
\hline - Good/normal & $18(54.5)$ & $18(54.5)$ & \multirow{2}{*}{1} \\
\hline - Poor & $15(45.5)$ & $15(45.5)$ & \\
\hline Operator & & & \\
\hline - Expert & $29(87.9)$ & $31(93.9)$ & \multirow{2}{*}{0.392} \\
\hline - Non-expert & $4(12.1)$ & $2(6.1)$ & \\
\hline
\end{tabular}


- Table 6 Comparison of treatment results between S-O clip use group and non-use group after propensity score matching.

\begin{tabular}{|c|c|c|c|}
\hline \multirow[t]{2}{*}{ Variables } & \multicolumn{2}{|l|}{ S-O clip } & \multirow[t]{2}{*}{$P$ value } \\
\hline & $\begin{array}{l}\text { Non-use } \\
n=33\end{array}$ & $\begin{array}{l}\text { Use } \\
n=33\end{array}$ & \\
\hline Procedure time (min) & $215 \pm 145$ & $110 \pm 40$ & 0.0697 \\
\hline En bloc resection & 30 (90.9 [76.4-96.9]) & $33(100.0[89.6-100.0])$ & 0.0763 \\
\hline Complete en bloc resection & $28(84.9[69.1-93.3])$ & $33(100.0[89.6-100.0])$ & 0.02 \\
\hline \multicolumn{4}{|l|}{ Adverse events } \\
\hline - Delayed bleeding & $0(0[0-9.1])$ & $2(6.1[1.7-19.6])$ & 0.151 \\
\hline - Perforation & $0(0[0-9.1])$ & $2(6.1[1.7-19.6])$ & 0.151 \\
\hline
\end{tabular}

On the contrary, in the internal traction method, such as use of the S-O clip, loop-attached rubber band, or latex band, lesions can be clipped at a desired position, and effective countertraction can be applied to a lesion independently from the scope. Thus, it is possible to improve the visual field while maintaining scope operability $[23,24,34,35]$. Notably, as the S-O clip can be passed through the forceps port of the scope, it is not necessary to reinsert the scope; therefore, it is also useful in the proximal colon. However, this technique is also associated with certain limitations. Once the $\mathrm{S}-\mathrm{O}$ clip is attached, it may be difficult to reattach the clip. Moreover, the spring part of the device may be damaged.

Our study has some limitations. First, it was a retrospective single-center study performed by seven endoscopists with various skill levels. Second, the study enrolled a relatively small number of patients. However, as the data from the use and non-use groups were adjusted by propensity score matching, the quality of the results of this study can be considered to be sufficient.

\section{Conclusion}

In conclusion, the S-O clip is effective and can be used safely in colorectal ESD in cases wherein the submucosal layer is difficult to access.

\section{Competing interests}

The authors declare that they have no conflict of interest.

\section{References}

[1] Tanaka S, Oka S, Kaneko I et al. Endoscopic submucosal dissection for colorectal neoplasia: possibility of standardization. Gastrointest Endosc 2007; 66: 100-107
[2] Tamegai Y, Saito Y, Masaki N et al. Endoscopic submucosal dissection: a safe technique for colorectal tumors. Endoscopy 2007; 39: 418-422

[3] Hurlstone DP, Atkinson R, Sanders DS et al. Achieving R0 resection in the colorectum using endoscopic submucosal dissection. $\mathrm{Br}$ J Surg 2007; 94: 1536-1542

[4] Tanaka S, Oka S, Chayama K. Colorectal endoscopic submucosal dissection: present status and future perspective, including its differentiation from endoscopic mucosal resection. J Gastroenterol 2008; 43: 641-651

[5] Saito Y, Fukuzawa M, Matsuda T et al. Clinical outcome of endoscopic submucosal dissection versus endoscopic mucosal resection of large colorectal tumors as determined by curative resection. Surg Endosc 2010; 24: 343-352

[6] Tanaka S, Tamegai Y, Tsuda S et al. Multicenter questionnaire survey on the current situation of colorectal endoscopic submucosal dissection in Japan. Dig Endosc 2010; 22: S2-S8

[7] Terasaki M, Tanaka S, Oka S et al. Clinical outcomes of endoscopic submucosal dissection and endoscopic mucosal resection for laterally spreading tumors larger than 20 mm. J Gastroenterol Hepatol 2012; 27: $734-740$

[8] Oka S, Tanaka S, Saito Y et al. Local recurrence after endoscopic resection for large colorectal neoplasia: a multicenter prospective study in Japan. Am J Gastroenterol 2015; 110: 697-707

[9] Boda K, Oka S, Tanaka S et al. Clinical outcomes of endoscopic submucosal dissection for colorectal tumors: a large multicenter retrospective study from the Hiroshima GI Endoscopy Research Group. Gastrointest Endosc 2018; 87: 714-722

[10] Matsumoto A, Tanaka S, Oba S et al. Outcome of endoscopic submucosal dissection for colorectal tumors accompanied by fibrosis. Scand J Gastroenterol 2010; 45: 1329-1337

[11] Hayashi N, Tanaka S, Nishiyama S et al. Predictors of incomplete resection and perforation associated with endoscopic submucosal dissection for colorectal tumors. Gastrointest Endosc 2014; 79: 427-435

[12] Lee BI. Debates on colorectal endoscopic submucosal dissection traction for effective dissection: gravity is enough. Clin Endosc 2013; 46: 467-471

[13] Saito Y, Emura F, Matsuda T et al. A new sinker-assisted endoscopic submucosal dissection for colorectal cancer. Gastrointest Endosc 2005; 62: 297-301

[14] Yamamoto K, Hayashi S, Saiki H et al. Endoscopic submucosal dissection for large superficial colorectal tumors using the "clip-flap method". Endoscopy 2015; 47: 262-265 
[15] Imaeda H, Hosoe N, Ida Y et al. Novel technique of endoscopic submucosal dissection by using external forceps for early rectal cancer (with videos). Gastrointest Endosc 2012; 75: 1253-1257

[16] Uraoka T, Kato J, Ishikawa $S$ et al. Thin endoscope-assisted endoscopic submucosal dissection for large colorectal tumors (with videos). Gastrointest Endosc 2007; 66: 836-839

[17] Uraoka T, Ishikawa S, Kato J et al. Advantages of using thin endoscope-assisted endoscopic submucosal dissection technique for large colorectal tumors. Dig Endosc 2010; 22: 186-191

[18] Yamasaki Y, Takeuchi Y, Hanaoka $\mathrm{N}$ et al. A novel traction method using an endoclip attached to a nylon string during colonic endoscopic submucosal dissection. Endoscopy 2015; 47: E238-E239

[19] Yamasaki Y, Takeuchi Y, Uedo N et al. Traction-assisted colonic endoscopic submucosal dissection using clip and line: a feasibility study. Endosc Int Open 2016; 4: E51-E55

[20] Ota R, Doyama H, Tsuji K et al. Deep colonic endoscopic submucosal dissection using a modified clip and snare method incorporating a pre-looping technique. BMJ Case Rep 2015; pii: bcr2014207918

[21] Yamada S, Doyama H, Ota R et al. Impact of the clip and snare method using the prelooping technique for colorectal endoscopic submucosal dissection. Endoscopy 2016; 48: 281-285

[22] Gotoda T, Oda I, Tamakawa K et al. Prospective clinical trial of magnetic-anchor-guided endoscopic submucosal dissection for large early gastric cancer (with videos). Gastrointest Endosc 2009; 69: 10-15

[23] Sakamoto N, Osada T, Shibuya T et al. The facilitation of a new traction device (S-O clip) assisting endoscopic submucosal dissection for superficial colorectal neoplasms. Endoscopy 2008; 40: E94-E95

[24] Sakamoto N, Osada T, Shibuya T et al. Endoscopic submucosal dissection of large colorectal tumors by using a novel spring-action S-O clip for traction (with video). Gastrointest Endosc 2009; 69: 13701374

[25] Nagata M. Modified attachment method using an S-O clip for gastric endoscopic submucosal dissection. VideoGIE 2019; 4: 151-153
[26] Hashimoto R, Hirasawa D, Iwaki T et al. Usefulness of the S-O clip for gastric endoscopic submucosal dissection (with video). Surg Endosc 2018; 32: 908-914

[27] Hashimoto R, Hirasawa D. Duodenal endoscopic submucosal dissection with traction method using the S-O clip. Dig Endosc 2017; 29: 635

[28] Ritsuno H, Sakamoto N, Osada T et al. Prospective clinical trial of traction device-assisted endoscopic submucosal dissection of large superficial colorectal tumors using the S-O clip. Surg Endosc 2014; 28: 3143-3149

[29] Tanaka S, Kashida H, Saito Y et al. JGES guidelines for colorectal endoscopic submucosal dissection/endoscopic mucosal resection. Dig Endosc 2015; 27: 417-434

[30] Tanaka S, Saitoh Y, Matsuda T et al. Evidence-based clinical practice guidelines for management of colorectal polyps. J Gastroenterol 2015; 50: 252-260

[31] Oka S, Tanaka S, Kanao H et al. Current status in the occurrence of postoperative bleeding, perforation and residual/local recurrence during colonoscopic treatment in Japan. Dig Endosc 2010; 22: 376-380

[32] Matsumoto A, Tanaka S, Oba S et al. Outcome of endoscopic submucosal dissection for colorectal tumors accompanied by fibrosis. Scand J Gastroenterol 2010; 45: 1329-1337

[33] Tajiri H, Kitano S. Complications associated with endoscopic mucosal resection: definition of bleeding that can be viewed as accidental. Dig Endosc 2004; 16: S134-S136

[34] Osada T, Sakamoto N, Shibuya T et al. "Loops-attached rubber band" facilitation of endoscopic submucosal dissection of superficial colorectal neoplasm. Endoscopy 2008; 40: E101-E102

[35] Tomiki Y, Ishiyama S, Sugimoto K et al. Colorectal endoscopic submucosal dissection by using latex-band traction. Endoscopy 2011; 43: E250-E251 